\title{
Effects of a hydroalcoholic extract of Juglans regia (walnut) leaves on blood glucose and major cardiovascular risk factors in type 2 diabetic patients: a double-blind, placebo-controlled clinical trial
}

Khadijeh Rabiei ${ }^{1}$, Mohammad Ali Ebrahimzadeh², Majid Saeedi ${ }^{2}$, Adele Bahar ${ }^{3}$, Ozra Akha ${ }^{3}$ and Zahra Kashi ${ }^{3,4^{*}}$ (D)

\begin{abstract}
Background: We aimed to evaluate the effects of a hydroalcoholic extract of Juglans regia L. leaves on blood glucose level and cardiovascular risk factors in type 2 diabetic patients.

Methods: In this randomized, double-blind, placebo-controlled, parallel-group (2 arms) clinical trial, 50 diabetic patients were divided into two groups: treatment group (receive the capsules containing $100 \mathrm{mg} \mathrm{J}$. regia leaf extract) and control group (receive the capsules containing placebo, microcrystallin cellulose). Baseline participant data were matched between the two arms of the study. We administered the prepared capsules to the patients twice daily for 8 weeks. Blood glucose level, glycosylated hemoglobin ( $\mathrm{HbA} 1 \mathrm{c}$ ) level, body weight, body mass index, blood pressure, lipid profile, serum insulin, and insulin resistance were compared between the two groups before and after the intervention. $P<0.05$ was considered significant.

Results: After excluding eleven patients, 20 received J. regia leaf extract and 20 patients received placebo. The J. regia leaf extract did not significantly change the blood glucose and insulin resistance condition. However, in this group, body weight, body mass index, and systolic blood pressure significantly decreased compared with the baseline measurements $(P=0.028, P=0.030$, and $P=0.005$, respectively). The lipid profile did not change significantly compared with the baseline measurements. In the control group, postprandial glucose and $\mathrm{HbA} 1 \mathrm{c}$ levels significantly decreased after the intervention $(P=0.030$ and $P=0.028$, respectively). The other variables were not significantly different in this group. At the end of the study, the variables were not significantly different between the two groups.

Conclusion: In this double-blind study, $200 \mathrm{mg} / \mathrm{d}$ of J. regia leaf extract had no significant effect on blood glucose level and HOMA-IR score in patients with type 2 diabetes. However, the J. regia leaf extract was effective in reducing body weight and blood pressure. An accidental finding of our study was that microcrystalline cellulose, a widely used placebo in clinical trials, led to a reduction in blood glucose level.
\end{abstract}

Trial registration: Iranian Registry of Clinical Trials (IRCT: 138901203180 N2, 2010/6/6); retrospectively registered.

Keywords: Diabetes mellitus, Juglans regia, Walnut leaves, Herbal medicine, Weight, Blood glucose, Blood pressure, Cardiovascular, Microcrystalline cellulose, Avicel

\footnotetext{
*Correspondence: kashi_zahra@yahoo.com

${ }^{3}$ Diabetes Research Center, Mazandaran University of Medical Sciences, Sari,

Iran

${ }^{4}$ Traditional and Complementary Medicine Research Center, Addiction

Institute, Mazandaran University of Medical Sciences, Sari, Iran

Full list of author information is available at the end of the article
}

(c) The Author(s). 2018 Open Access This article is distributed under the terms of the Creative Commons Attribution 4.0 International License (http://creativecommons.org/licenses/by/4.0/), which permits unrestricted use, distribution, and reproduction in any medium, provided you give appropriate credit to the original author(s) and the source, provide a link to the Creative Commons license, and indicate if changes were made. The Creative Commons Public Domain Dedication waiver (http://creativecommons.org/publicdomain/zero/1.0/) applies to the data made available in this article, unless otherwise stated. 


\section{Background}

Diabetes mellitus is an important metabolic disease and the most prevalent chronic illness around the world with a high financial burden. According to the World Health Organization report, 422 million people have diabetes worldwide, and this rate is rising rapidly [1].

Diet, exercise, and medications are used to manage the disease. However, most patients are reluctant to use chemical drugs, and sometimes, they do not achieve adequate disease control despite the use of multiple medications [2]. The management of cardiovascular risk factors, including weight, lipid levels, and blood pressure, in addition to blood glucose, is very important in patients with type 2 diabetes mellitus [3]. The available anti-diabetic drugs have different effects on the cardiovascular risk factors in diabetic patients, with some of them having a positive effect and some a negative effect. Currently, researchers are giving special attention to the use of medicinal herbs for the treatment of various diseases. The leaves of Juglans regia L. (J. regia) have been used in traditional medicines as an antimicrobial, anthelmintic, keratolytic, and antidiarrheal and are rich in polyphenolic compounds and flavonoids [4] Amongst the several categories of phytochemicals, polyphenols are the most attractive ones, especially for medicinal purposes [5]. Polyphenols are an important class of secondary metabolites of the plant, possessing a variety of pharmacological activities. Plant phenolics are multifunctional and can act as reducing agents, metal chelators, and singlet oxygen quenchers [6]. Several polyphenols have been shown to have significant antioxidant activities through in vitro and in vivo studies [5]. Studies have shown that consumption of foods and beverages rich in phenolic content is correlated with a reduced risk of atherosclerosis and cardiovascular disease [7]. Literature review shows that polyphenols have demonstrated beneficial effects in animal models of several cardiovascular disorders like hypertension, atherosclerosis, endothelial dysfunction, dyslipidemia, and diabetes-related cardiovascular complications [5] Flavonoids form a ubiquitous group of polyphenolic substances typically produced by plants. Flavonoids are of great interest because of their bioactivities, which are basically related to their antioxidant properties [8]. It has been recognized that flavonoids show antioxidant activity, and their effects on human nutrition and health are considerable. Flavonoids may slow the pathogenesis of atherosclerosis and cardiovascular diseases by their ROS scavenging effects. The mechanism of action of flavonoids involves a scavenging or chelating process [8].

Some studies have reported the anti-diabetic effects of $J$. regia leaves in rats [9-11]; nevertheless, the number of human studies is few. The present study was designed to evaluate the effect of a hydroalcoholic extract of $J$. regia leaves on hyperglycemia and cardiovascular risk factors in patients with type 2 diabetes mellitus.

\section{Methods}

This study was a randomized, double-blind, placebo-controlled, parallel group clinical trial. We evaluated the effect of a hydroalcoholic extract of $J$. regia leaves on blood glucose as the primary outcome and insulin resistance, lipid profile, blood pressure, and body weight, the cardiac risk factors, as the secondary outcomes in type 2 diabetic patients.

\section{Preparation of the formulations plant material}

J. regia (Juglandaceae) leaf was collected from Dashtenaz area, Sari, Iran. After identification by Dr. Bahman Eslami (Assistance professor of plant systematic, Islamic Azad University, Branch of Ghaemshahr, Iran), Voucher specimen (No 629) was deposited in the Sari School of Pharmacy. The sample was dried at room temperature on the ground before extraction. One kilogram of the sample was extracted by percolation with $70 \%$ ethanol $(2.5 \mathrm{~L} \times 3)$ for $24 \mathrm{~h}[12-14]$. The resultant extracts were concentrated in a rotary evaporator until a solid crude extract was obtained, which was freeze-dried to remove the solvent $(15.5 \%)$ completely. The dried extracts were powdered and mixed with microcrystalline cellulose (Avicel) and then were encapsulated. Avicel was purchased from Sigma-Aldrich (USA). Each capsule contained $100 \mathrm{mg}$ extract and $400 \mathrm{mg}$ Avicel. Avicel itself was used as placebo. Each placebo capsule contained $500 \mathrm{mg}$ Avicel. The final formulations were controlled microbiologically based on the United States Pharmacopeia (USP) method [15].

\section{Standardization of extract}

The extract was standardized based on the phenol content. The total phenolic content was determined using the Folin-Ciocalteu method [16] . Each capsule contained $40 \mathrm{mg} \pm 1.3 \mathrm{mg}$ gallic acid equivalent per gram extract.

\section{Study design}

The participants in the study were selected from among those referred to the diabetes outpatient academic clinic in Imam Khomeini Hospital, Sari, Iran (2012-2013). The inclusion criteria were an age of 30-80 years and glycosylated hemoglobin (HbA1c) level more than $7 \%$ in spite of receiving the maximal dose of two anti-diabetic drugs (metformin and glibenclamide). Patients were not included in the study if they had immunodeficiency, uncontrolled thyroid dysfunction, cardiovascular disease, proliferative retinopathy, acute hepatitis or cirrhosis, acute infection, history of diabetic ketoacidosis, severe weight loss (at least 10\% during the past 6 months), current corticosteroid or thiazide consumption, and serum creatinine $(\mathrm{Cr})$ level $>1.5 \mathrm{mg} / \mathrm{dl}$ in males and $>$ $1.4 \mathrm{mg} / \mathrm{dl}$ in females. The exclusion criteria also included 
pregnancy, lactation, changes in anti-diabetic drug type, and lack of follow-up.

Fifty eligible type 2 diabetic patients were enrolled in the study. The minimum sample size was determined to be 20 patients in each group for a statistical power of 0.8 and 95\% confidence level and treatment effect size of 0.5-0.8 decrease in the HbA1C following the intervention. After being explained about the trial, the patients signed an informed consent form and were randomly (manual methods and sequentially numbered envelopes) divided into two groups (by a trained general physician who was blind to the content of the capsules), J. regia leaves group or the placebo capsule group. The fasting blood sugar (FBS), postprandial glucose (PPG), HbAlc, HOMA-IR, body weight, and blood pressure (BP) were not different between the two groups at baseline. (Table 1) All the patients were advised not to change their previous medications and standard diet during the study period.

The drug or placebo was administered by a trained physician once per day for 1 week and then twice per day for 7 weeks. Body weight, body mass index (BMI), BP, FBS, serum insulin, HbA1c, PPG, serum lipid profile, and liver function were measured at baseline and after treatment. A general physician, who was blinded to the treatment type, examined the patients after 2 weeks and 8 weeks and counted the number of the remaining capsules for the assessment of the participants' adherence to the interventions. Insulin resistance was calculated using the homeostasis model assessment-estimated insulin resistance (HOMA-IR) method [17] .

$$
\begin{array}{r}
H O M A_{I R}=\text { fasting plasma insulin } \mathrm{mIU} / \mathrm{L} \\
\times \text { fasting plasma glucose } \frac{\mathrm{mmol} / \mathrm{L}}{22.5}
\end{array}
$$

\section{Statistical analysis}

The analysis was according to the original assigned groups. Student's t-test and paired t-test were used to compare the quantitative variables between the two groups and the before-after values of each group, respectively. The qualitative variables were compared between the two groups using Chi-square test and Fisher exact test, if necessary. In all calculations, $P<0.05$ was considered to be significant.

\section{Results}

In this study, 25 patients were assigned to the intervention group, and 25 patients were assigned to the control group (2012 until 2013). However, because of the changes in the anti-diabetic drug type or lack of follow-up, five patients in the extract group and six patients in the control group were excluded from the study. Fig 1.

\begin{tabular}{|c|c|c|c|}
\hline Variable & Juglans regia leaves group $n(N=25)$ Mean $\pm S D$ & placebo group $(N=25)$ Mean $\pm S D$ & $P$ value \\
\hline Weight (kg) & $74.5 \pm 15.4$ & $73.1 \pm 9.2$ & 0.744 \\
\hline BMI $\left(\mathrm{kg} / \mathrm{cm}^{2}\right)$ & $29.7 \pm 5.8$ & $30.2 \pm 3.8$ & 0.738 \\
\hline Systolic blood pressure $(\mathrm{mm} \mathrm{Hg})$ & $126.4 \pm 9.1$ & $121.7 \pm 10.5$ & 0.153 \\
\hline Diastolic blood pressure (mm Hg) & $79.7 \pm 6.7$ & $76.7 \pm 9.8$ & 0.275 \\
\hline Fasting blood glucose (mg/dl) & $195.2 \pm 38.2$ & $205 \pm 51.9$ & 0.500 \\
\hline Postprandial blood glucose (mg/dl) & $283.8 \pm 45.5$ & $303.2 \pm 68.1$ & 0.323 \\
\hline $\mathrm{HbA1C}(\%)$ & $9.6 \pm 1.1$ & $9.8 \pm 0.8$ & 0.421 \\
\hline Insulin level & $7.2 \pm 5$ & $6.4 \pm 3.2$ & 0.598 \\
\hline HOMA IR & $3.6 \pm 2.9$ & $2.9 \pm 1.6$ & 0.451 \\
\hline Creatinine (mg/dl) & $0.8 \pm 0.1$ & $0.9 \pm 0.2$ & 0.671 \\
\hline Hemoglobin (mg/dl) & $12.8 \pm 1.8$ & $12.4 \pm 1.3$ & 0.458 \\
\hline Cholesterol (mg/dl) & $176.4 \pm 39.7$ & $183.4 \pm 31.5$ & 0.547 \\
\hline Triglyceride (mg/dl) & $180 \pm 81.7$ & $167.8 \pm 76.6$ & 0.631 \\
\hline HDL Cholesterol (mg/dl) & $49.3 \pm 8.9$ & $46 \pm 12.8$ & 0.336 \\
\hline LDL Cholesterol (mg/dl) & $92.5 \pm 30.1$ & $102.2 \pm 22.3$ & 0.257 \\
\hline AST (U/L) & $18.9 \pm 4$ & $24.4 \pm 9.7$ & 0.022 \\
\hline $\mathrm{ALT}(\mathrm{U} / \mathrm{L})$ & $20 \pm 6.2$ & $25.2 \pm 13$ & 0.114 \\
\hline ALP (IU/L) & $196.9 \pm 59.1$ & $214.1 \pm 55.1$ & 0.347 \\
\hline TSH (IU/L) & $2.2 \pm 1.2$ & $2.4 \pm 0.9$ & 0.716 \\
\hline
\end{tabular}

Table 1 Baseline participant data in two arms, Juglans regia leaves group and control group $(n=50)$ 


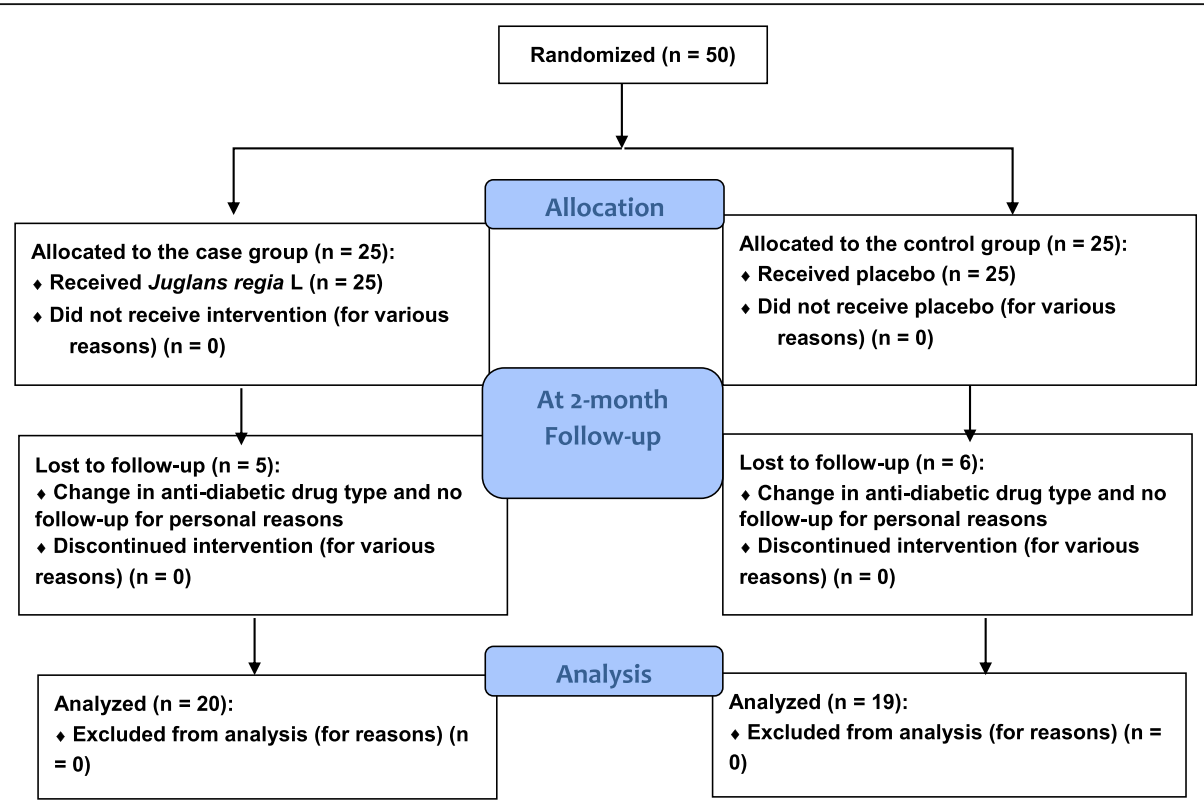

Fig. 1 Study flow diagram based on the CONSORT 2010 flow diagram

The mean age of the patients was not significantly different between the intervention group $(50.5 \pm 8.3$ years $)$ and the control group $(49.9 \pm 8.6$ years $)(P=0.84)$. There was a history of hypertension and dyslipidemia in 52.4 and $85.7 \%$ of the participants in the intervention group, respectively, and 42.1 and $84.2 \%$ in the control group, respectively ( $P=0.5$ for hypertension and $P=0.9$ for dyslipidemia). Most of the participants were female; there were 18 females in the control group and 19 females in the intervention group $(P=0.08)$.

The J. regia leaves extract had no significant effect on the FBS, PGG, HbA1c level, insulin resistance, and lipid profile, but $J$. regia leaves extract significantly decreased the body weight, BMI, and systolic BP compared with the baseline measurements $(P=0.028, P=0.030$, and $P=0.005$, respectively). In the control group, the PGG, $\mathrm{HbA1c}$, and alanine transaminase (ALT) levels decreased significantly after the intervention $(\mathrm{P}=0.030, \mathrm{P}=0.028$ and $P=0.044$, respectively). Although the aspartate transaminase (AST) level was higher in the placebo group at baseline, there were no significant differences in any of the variables between the two groups at the end of the study (Table 2). The participants in the treatment and control group reported no side effects.

\section{Discussion}

The use of $J$. regia leaves for the management of diabetes mellitus has been described in the Iranian traditional medicine [18].

In the present study, the J. regia leaves had no significant effect on the blood glucose and HOMA-IR levels in the diabetic patients. However, the leaf extract significantly decreased the body weight and systolic BP without any adverse effects on the liver and kidney function.

According to the literature on traditional medicines, the herbal medicines and their extracts are useful in the treatment of chronic disorders, including diabetes mellitus. The herbal medicines have a protective and therapeutic effect in diabetes mellitus via regeneration of the pancreatic $\beta$ cell, glycogen degradation, decreased gluconeogenesis, $\alpha$-glucosidase enzyme inhibitor activity, and antioxidative stress $[19,20]$.

Some previous studies investigated the effect of $J$. regia leaves in rats and showed that it had a positive effect on the blood glucose level. They reported that the hypercellularity of the pancreatic islet tissue was associated with increased hyperchromic nucleus of the islet cells. This finding may be indicative of regeneration of the beta cells [9]. According to the study by Kamyab et al. [21] in mice, oral walnut leaf and ridge extracts significantly reduced liver pyruvate carboxykinase activity and increased liver glycogen phosphorylase activity. They concluded that walnut could reduce the blood glucose level by inhibiting hepatic gluconeogenesis and stimulating secretion of pancreatic insulin.

There are a few scientific studies on the anti-diabetic effect of $J$. regia leaves in humans. We found only two human studies that looked at the effect of $J$. regia leaves in patients with type 2 diabetes $[13,22]$. Both studies were done in Iran and reported the significant effect of this plant on blood glucose and insulin levels. However, in the study by Hosseini et al. [13], the plant extract was not standardized, and it was not clear what the placebo was. Also, the researchers 
Table 2 Participant data before and after intervention in the case group (extract of Juglans regia leaves) and the placebo group (Avicel)

\begin{tabular}{|c|c|c|c|c|c|c|}
\hline \multirow[t]{2}{*}{ Variable } & \multicolumn{2}{|c|}{ Juglans regia leaves group $+(N=20)$} & \multirow[t]{2}{*}{$P$ value } & \multicolumn{2}{|c|}{ placebo group $(N=19)$} & \multirow[t]{2}{*}{$P$ value } \\
\hline & $\begin{array}{l}\text { Before intervention } \\
\text { Mean } \pm \text { SD }\end{array}$ & $\begin{array}{l}\text { After intervention } \\
\text { Mean } \pm \text { SD }\end{array}$ & & $\begin{array}{l}\text { Before intervention } \\
\text { Mean } \pm \text { SD }\end{array}$ & $\begin{array}{l}\text { After intervention } \\
\text { Mean } \pm \text { SD }\end{array}$ & \\
\hline Weight (kg) & $73.0 \pm 15.1$ & $71.7 \pm 13.8$ & 0.028 & $73.2 \pm 9.2$ & $72.3 \pm 8.7$ & 0.303 \\
\hline $\mathrm{BMI}\left(\mathrm{kg} / \mathrm{cm}^{2}\right)$ & $29.2 \pm 6.0$ & $28.7 \pm 5.3$ & 0.030 & $30.3 \pm 3.9$ & $29.9 \pm 4.0$ & 0.336 \\
\hline $\begin{array}{l}\text { Systolic blood pressure (mm } \\
\mathrm{Hg} \text { ) }\end{array}$ & $126.1 \pm 9.5$ & $121.1 \pm 8.8$ & 0.005 & $121.8 \pm 10.6$ & $120.6 \pm 9.7$ & 0.637 \\
\hline $\begin{array}{l}\text { Diastolic blood pressure } \\
(\mathrm{mm} \mathrm{Hg})\end{array}$ & $79.2 \pm 6.7$ & $77.4 \pm 4.8$ & 0.185 & $76.8 \pm 9.8$ & $79.7 \pm 4.8$ & 0.116 \\
\hline $\begin{array}{l}\text { Fasting blood glucose (mg/ } \\
\text { dl) }\end{array}$ & $191.7 \pm 36.6$ & $179.5 \pm 49.0$ & 0.309 & $205.1 \pm 51.9$ & $194.6 \pm 64.8$ & 0.447 \\
\hline $\begin{array}{l}\text { Postprandial blood glucose } \\
(\mathrm{mg} / \mathrm{dl})\end{array}$ & $283.2 \pm 46.8$ & $307.7 \pm 99.0$ & 0.249 & $303.2 \pm 68.2$ & $255.4 \pm 53.7$ & 0.030 \\
\hline $\mathrm{HbA1C}(\%)$ & $9.6 \pm 1.1$ & $9.5 \pm 1.8$ & 0.646 & $9.90 \pm 0.9$ & $9.1 \pm 1.3$ & 0.028 \\
\hline Insulin level & $6.4 \pm 3.7$ & $7.3 \pm 3.9$ & 0.447 & $6.2 \pm 3.3$ & $4.5 \pm 3.1$ & 0.139 \\
\hline HOMA IR & $3.3 \pm 2.7$ & $2.9 \pm 2.2$ & 0.186 & $3.0 \pm 1.7$ & $2.7 \pm 1.4$ & 0.395 \\
\hline Creatinine (mg/dl) & $0.9 \pm 0.2$ & $0.8 \pm 0.2$ & 0.474 & $0.9 \pm 0.2$ & $0.8 \pm 0.2$ & 0.270 \\
\hline Hemoglobin (mg/dl) & $12.8 \pm 1.9$ & $13.2 \pm 2.0$ & 0.119 & $12.5 \pm 1.3$ & $12.3 \pm 1.2$ & 0.601 \\
\hline Cholesterol (mg/dl) & $176.5 \pm 41.8$ & $169.0 \pm 30.5$ & 0.413 & $183.4 \pm 31.6$ & $176.5 \pm 35.8$ & 0.495 \\
\hline Triglyceride (mg/dl) & $179.7 \pm 86.1$ & $170.6 \pm 81.9$ & 0.622 & $167.8 \pm 76.7$ & $184.1 \pm 105.6$ & 0.276 \\
\hline HDL Cholesterol (mg/dl) & $49.0 \pm 9.3$ & $51.1 \pm 9.1$ & 0.337 & $44.9 \pm 12.2$ & $46.2 \pm 13.6$ & 0.710 \\
\hline LDL Cholesterol (mg/dl) & $93.2 \pm 31.6$ & $83.5 \pm 16.0$ & 0.151 & $102.3 \pm 22.3$ & $93.0 \pm 15.7$ & 0.187 \\
\hline AST (U/L) & $19.1 \pm 4.2$ & $19.2 \pm 6.2$ & 0.902 & $23.9 \pm 9.6$ & $19.4 \pm 6.7$ & 0.056 \\
\hline $\mathrm{ALT}(\mathrm{U} / \mathrm{L})$ & $20.7 \pm 6.5$ & $20.2 \pm 8.1$ & 0.803 & $24.7 \pm 12.4$ & $18.3 \pm 5.7$ & 0.044 \\
\hline ALP (IU/L) & $200.7 \pm 61.3$ & $197.4 \pm 68.0$ & 0.817 & $202.9 \pm 51.1$ & $194 . .6 \pm 64.2$ & 0.594 \\
\hline TSH (IU/L) & $2.2 \pm 1.2$ & - & - & $2.4 \pm 0.9$ & - & - \\
\hline
\end{tabular}

There were no significant differences in any of the variables between the two groups at the end of the study

These entries are in boldface because these variables significantly changed after internention $(p$ value $<0.05)$

prepared the plant extract and placebo in a tablet form, which can affect the double blinding of the study because of the smell of walnut. In a study by Abdoli et al. [22], the aqueous extract of $J$. regia leaves had significant blood glucose lowering effect in patients with type 2 diabetes. The baseline fasting plasma glucose was significantly lower than that in the control group in the study by Abdoli et al. Also, toast powder was used as the placebo in this study, which may itself increase the blood glucose levels [23].

In the present study, we used microcrystalline cellulose (Avicel) as the placebo. Microcrystalline cellulose is an insoluble fiber. When given orally, the agent is not absorbed and has no toxicity; therefore, it is widely used as a placebo in clinical trials [24, 25]. Surprisingly, in our study, low dose of Avicel taken orally (1000 mg/day) significantly lowered the PPG and HbA1c. We did not find any published article on the effect of microcrystalline cellulose (Avicel) on blood glucose in humans. In the study by Takahashi et al. [23] in rats, the consumption of cellulose with meals increased the digestive viscosity and modulated the postprandial plasma glucose.
In our study, the extract of J. regia leaves had a significant effect on the body weight and BP. Neither Hosseini et al. [13] nor Abdoli et al. [22] reported about the effect of the extract of J. regia leaves on the body weight or BP. Ma et al. [26]. evaluated the effects of a walnut-enriched diet on the endothelial function in patients with type 2 diabetes and reported a significant improvement in the endothelial function and BP. However, the walnut-enriched diet had no significant effect on the blood glucose, HbA1c, and insulin sensitivity. In our study, the consumption of J. regia leaves extract led to a significant reduction in the body weight. This effect was also reported by Rock et al. [27] in obese men and women who were given a walnut-enriched diet. We did not find a positive or negative effect of $J$. regia leaves on the lipid profile. Though Hosseini et al. [13] reported the hypolipidemic effects of J. regia leaves, Abdoli et al. [22] did not find a positive effect similar to our study. In the study by Ma et al., the walnut-enriched diet had no significant effect on lipid profile.

One of the limitations of our study was that most of the patients were female, although gender did not 
appear to have a significant effect on the participants' response to the plant extract [28]. Another limitation was the short duration of our study.

\section{Conclusion}

The main finding of our study is that the J. regia leaves extract is effective in decreasing some major cardiovascular risk factors including body weight and $\mathrm{BP}$ in patients with type 2 diabetes. However, the extract had no significant effect on the blood glucose, HOMA-IR, and lipid profile. An accidental finding of our study was that microcrystalline cellulose, which is widely used as a placebo in clinical trials, led to a reduction in the blood glucose level, particularly the PPG. The J. regia leaves had no side effects and were safe in low dose $(200 \mathrm{mg} / \mathrm{d})$ in our study. These results can be important for researchers who want use this agent as a placebo in clinical trials. On the other hand, this finding may be the first step for future studies to use this substance as a hypoglycemic drug.

\section{Abbreviations}

ALT: Alanine transaminase; AST: Aspartate aminotransferase; BMI: body mass index; BP: blood pressure; Cr: Creatinine; FBS: Fasting blood sugar; HbA1c: glycosylated hemoglobin; HOMA-IR: homeostasis model assessment method-insulin resistance; J. regia: Juglans regia L.; PPG: postprandial blood glucose; USP: United States pharmacopeia

\section{Acknowledgements}

This paper is derived from a research proposal approved by research committee Traditional and Complementary Medicine Research Center. We sincerely thank the patients who trusted us to perform the study. We sincerely thank Dr. Mohhamadpour for statistical analysis helping.

\section{Funding}

This research was supported by the Mazandaran University of Medical Sciences.

\section{Availability of data and materials}

All the data is available with Dr. Zahra Kashi, reasonable request will be responded with supplementary raw-data.

\section{Authors' contributions}

ZK, KHR: Designer and project manager, Sample collection, Article writing. $A B, O A$ : Designer, Sample collection, Article writing. MAE, MS: designer and preparing the drug and placebo, Article writing. All authors read and approved the final manuscript.

\section{Ethics approval and consent to participate}

The Ethical Committee of the Mazandaran University of Medical Sciences approved the present study (ethics approval reference number: 144-88). After explaining the trial, patients signed an informed consent form.

\section{Consent for publication}

"Not Applicable".

\section{Competing interests}

None.

\section{Publisher's Note}

Springer Nature remains neutral with regard to jurisdictional claims in published maps and institutional affiliations.

\section{Author details}

${ }^{1}$ World Federation of Acupunture-Moxibustion Societies (WFAS), Scientific Studies Institute of Nadali Esmaeili, Acupuncture Center, Sari, Iran.
${ }^{2}$ Pharmaceutical Sciences Research Center, Hemoglobinopathy Institute, Mazandaran University of Medical Sciences, Sari, Iran. ${ }^{3}$ Diabetes Research Center, Mazandaran University of Medical Sciences, Sari, Iran. ${ }^{4}$ Traditional and Complementary Medicine Research Center, Addiction Institute, Mazandaran University of Medical Sciences, Sari, Iran.

Received: 29 March 2018 Accepted: 22 June 2018

Published online: 04 July 2018

\section{References}

1. Mathers $C D$, Loncar D. Projections of global mortality and burden of disease from 2002 to 2030. PLoS Med. 2006;3(11):e442.

2. Schmieder RE, Tschope D, Koch C, Ouarrak T, Gitt AK. Individualised treatment targets in patients with type-2 diabetes and hypertension. Cardiovasc Diabetol. 2018;17(1):18.

3. Kurukulasuriya LR, Sowers JR. Therapies for type 2 diabetes: lowering HbA1C and associated cardiovascular risk factors. Cardiovasc Diabetol. 2010;9:45.

4. Qureshi MN, Stecher G, Bonn GK. Determination of total polyphenolic compounds and flavonoids in Juglans regia leaves. Pak J Pharm Sci. 2014; 27(4):865-9.

5. Bahramsoltani R, Ebrahimi F, Farzaei MH, Baratpourmoghaddam A, Ahmadi P, Rostamiasrabadi P, Rasouli Amirabadi AH, Rahimi R. Dietary polyphenols for atherosclerosis: a comprehensive review and future perspectives. Crit Rev Food Sci Nutr. 2017:11:1-19.

6. Rabiei K, Bekhradnia S, Nabavi SM, Nabavi SF, Ebrahimzadeh MA. Antioxidant activity of polyphenol and ultrasonic extracts from fruits of Crataegus pentagyna subsp. elburensis. Nat Prod Res. 2012;26(24):2353-7.

7. Manach C, Mazur A, Scalbert A. Polyphenols and prevention of cardiovascular diseases. Curr Opin Lipidol. 2005;16(1):77-84.

8. Naginezhad A, Nabavi SM, Nabavi SF, Ebrahimzadeh MA. Antioxidant and antihemolytic activities of flavonoid rich fractions of Artemisia tschernieviana Besser. Eur Rev Med Pharmacol Sci. 2012;16(Suppl 3):88-94.

9. Jelodar G, Mohsen M, Shahram S. Effect of walnut leaf, coriander and pomegranate on blood glucose and histopathology of pancreas of alloxan induced diabetic rats. Afr J Tradit Complement Altern Med. 2007:4(3):299-305.

10. Gholamreza K, Hossein B. Effects of walnut leaf aqueous extract on blood sugar and lipids in male diabetic rats. Saudi Med J. 2008;29(9):1350-2.

11. Asgary S, Parkhideh S, Solhpour A, Madani H, Mahzouni P, Rahimi P. Effect of ethanolic extract of Juglans regia L. on blood sugar in diabetes-induced rats. J Med Food. 2008;11(3):533-8.

12. Akhondzadeh S, Sabet MS, Harirchian MH, Togha M, Cheraghmakani $H$, Razeghi S, Hejazi S, Yousefi MH, Alimardani R, Jamshidi A, et al. Saffron in the treatment of patients with mild to moderate Alzheimer's disease: a 16-week, randomized and placebo-controlled trial. J Clin Pharm Ther. 2010;35(5):581-8.

13. Hosseini S, Huseini HF, Larijani B, Mohammad K, Najmizadeh A, Nourijelyani $\mathrm{K}$, Jamshidi L. The hypoglycemic effect of Juglans regia leaves aqueous extract in diabetic patients: a first human trial. Daru. 2014;22(1):19.

14. Cui $Y$, Tao Y, Jiang L, Shen N, Wang S, Wen H, Liu Z. Antihypoxic activities of constituents from Arenaria kansuensis. Phytomedicine : Int J Phytotherapy and Phytopharmacology. 2018;38:175-82.

15. The United States Pharmacopeia (USP 39). In. USA. Baltimore: United Book Press Inc; 2016. p. 111-42.

16. Ghasemi K, Ghasemi Y, Ebrahimzadeh MA. Antioxidant activity, phenol and flavonoid contents of 13 citrus species peels and tissues. Pak J Pharm Sci. 2009:22(3):277-81.

17. Wallace TM, Matthews DR. The assessment of insulin resistance in man. Diabet Med. 2002;19(7):527-34.

18. Zargari A. Medical plants. Tehran: Tehran University Press; 1990.

19. Farzaei F, Morovati MR, Farjadmand F, Farzaei MH. A mechanistic review on medicinal plants used for diabetes mellitus in traditional Persian medicine. J Evid Based Complementary Altern Med. 2017;22(4):944-55.

20. Farzaei MH, Rahimi R, Farzaei F, Abdollahi M. Traditional medicinal herbs for the Management of Diabetes and its complications: an evidence-based review. Int J Pharmacol. 2015:11(7):14.

21. Kamyab H, Hejrati S, Khanavi M, Malihi F, Mohammadirad A, Baeeri M, Esmaily H, Abdollahi M. Hepatic mechanisms of the walnut antidiabetic effect in mice. Central Eur J Biol. 2010;5(3):304-9.

22. Abdoli M, Dabaghian FH, Goushegir A, Shirazi MT, Nakhjavani M, Shojaii A, Rezvani S, Mahlooji K. Anti-hyperglycemic effect of aqueous extract of 
Juglans regia L. leaf (walnut leaf) on type 2 diabetic patients: a randomized controlled trial. Advances in Integrative Med. 2017;4(3): 98-102.

23. Takahashi T, Karita S, Ogawa N, Goto M. Crystalline cellulose reduces plasma glucose concentrations and stimulates water absorption by increasing the digesta viscosity in rats. J Nutr. 2005;135(10):2405-10.

24. Arnaud M. Chronic venous disorders: pharmacological and clinical aspects of micronized purified flavonoid fraction. Phlebolymphology. 2016;23(2):8.

25. Rowe RC, Sheskey PJ, Quinn ME, Association AP. In: Rowe RC, Sheskey PJ, Quinn ME, editors. Handbook of pharmaceutical excipients. 6th ed. EDN England: London; Chicago : Washington, DC: Pharmaceutical Press; American Pharmacists Association; 2009

26. Ma Y, Njike VY, Millet J, Dutta S, Doughty K, Treu JA, Katz DL. Effects of walnut consumption on endothelial function in type 2 diabetic subjects: a randomized controlled crossover trial. Diabetes Care. 2010;33(2):227-32.

27. Rock CL, Flatt SW, Barkai HS, Pakiz B, Heath DD. Walnut consumption in a weight reduction intervention: effects on body weight, biological measures, blood pressure and satiety. Nutr J. 2017:16(1):76.

28. Gale EAM, Gillespie KM. Diabetes and gender. Diabetologia. 2001;44(1):3-15.

\section{Ready to submit your research? Choose BMC and benefit from:}

- fast, convenient online submission

- thorough peer review by experienced researchers in your field

- rapid publication on acceptance

- support for research data, including large and complex data types

- gold Open Access which fosters wider collaboration and increased citations

- maximum visibility for your research: over $100 \mathrm{M}$ website views per year

At BMC, research is always in progress.

Learn more biomedcentral.com/submissions 